\title{
The State of the Art of Energy Harvesting and Storage in Silk Fibroin-Based Wearable and Implantable Devices
}

\author{
Ravi Moreno Araújo Pinheiro Lima, Mário César Albuquerque de Oliveira \\ and Helinando Pequeno de Oliveira *(D) \\ Institute of Materials Science, Universidade Federal do Vale do São Francisco, Juazeiro 48920-310, Bahia, Brazil; \\ ravi.lima@discente.univasf.edu.br (R.M.A.P.L.); mario.oliveira@discente.univasf.edu.br (M.C.A.d.O.) \\ * Correspondence: helinando.oliveira@univasf.edu.br
}

Received: 2 September 2020; Accepted: 28 September 2020; Published: 2 October 2020

check for updates

\begin{abstract}
The energy autonomy of self-powered wearable electronics depends on the adequate development of new technologies for energy harvesting and energy storage devices based on textile fibers to facilitate the integration with truly flexible and wearable devices. Silk fiber-based systems are attractive for the design of biomedical devices, lithium-ion batteries and flexible supercapacitors, due to their nitrogen-rich structure (for preparation of hierarchical carbon-based structures), and available surface for chemical modification reinforcing electroactive properties for use in batteries and supercapacitors. Herein, this paper reviews recent advances on silk fiber-based systems for harvesting and the storage of energy and the corresponding strategies to reinforce the physical and chemical properties of the resulting composites applied as electrodes and battery separators.
\end{abstract}

Keywords: silk fibroin; hierarchical structures; porosity; pseudocapacitance; wearable devices

\section{Introduction}

Conventional electronics based on inorganic semiconductors have been proved strong miniaturization in the last decades, reaching the limit of saturation in the integration level and relying on the rigidity of materials that present poor biocompatibility/biodegradability, a required property for actuators at soft interfaces such as biological surfaces [1,2].

The "green" electronics area is preconized as an emerging concept in which natural-based materials enrich properties, such as environmentally safe and biomedical applications for new devices [3]. Based on this concept, the literature has witnessed a recent revolution form development of smart textiles (e-textiles) that concerns to the integration of desirable electroconductive properties of electronic devices [4] with softness, biocompatibility, biodegradability and effective cost of production [5] of new materials in an environmentally responsible process for the production of electronic sensors and actuators.

Health monitoring and fitting tracking are the most recent applications for e-textiles [6] with promising properties for use in wound dressing systems, Joule heaters, antibacterial agents and energy storage devices [7]. The continuous development in the area of all-flexible e-textiles requires the integration of devices such as antennas, information processors, light sources, sensors and actuators, being required a high degree of autonomy. The availability of energy sources is a driven force for the production of wearable energy storage and energy harvesting devices that must be integrated with these devices under the condition of invariance in the response under different mechanical efforts (bending and stretching) and washing procedures [8,9].

The concepts of green electronics suggest that e-textile devices could be made by traditional and ancient textiles such as cotton and silk fibers. In particular, Bombyx mori silk fiber (known as 
the "queen of textiles") is a material produced by silkworms which are composed of a fibrous core made of silk fibroin proteins, a heterodimer of fibroin heavy chain and light chain proteins [5] coated with sericin [10], which is an outer coating layer [5]; the degumming process that removes sericin from the structure is usually conducted in sodium carbonate solution [11]. With the removal of the outer layer of sericin, the overall processing of silk fibroin has been explored for the production of membranes, hydrogels, aerogels, powder, tubes, films and alternative configurations $[5,12]$ that explore the abundance of hydrogen bonds on its backbone for the following chemical modification and incorporation of additives [10].

Despite this variety of available microstructures, the poor electrical properties of silk fibroin (SF) represents an important drawback to be circumvented in the development of e-textiles. The adequate modification of silk fibroin with additives such as conducting polymers [13-16], metal oxide and metal nanoparticles results in a reasonable level of conductivity for fibers while preserves the mechanical properties, that have been reinforced (impact/compression properties) by preparation of composites with epoxy [17-19] and by incorporation of graphene derivatives [20-23] for the following step of reduction of graphene oxide(GO), reinforcing properties such as anti-ultraviolet and water repellent activity. With these modifications in the intrinsic properties of the silk fibers, electroactive smart textile-based on silk fibroin can be considered as good templates for applications involving the shielding of electromagnetic radiation, dissipation of microwave energy, heat generation, etc. [16].

Different methods have been explored to incorporate high conductivity levels for silk-fibroin based systems, which are based on the interaction of fiber with fillers, such as carbon derivatives (graphene and carbon nanostructures), conducting polymers (polypyrrole, polyaniline, PEDOT: PSS) and gold/silver nanoparticles. These methods for surface modification are based on solution casting [24], dry-pun, $\mathrm{LbL}$, chemical polymerization, reduction of metal ions to metal nanoparticles [25], etc. On the other hand, the carbonization makes use of the rich structure of silk fibroins to produced N-doped porous carbon, with advantages for pseudocapacitive based-materials applied as electrodes of supercapacitors and anode of batteries.

Silk-fibroin based composites with superior electroconductive and mechanical properties have been considered as potential templates for different applications, as summarized in Scheme of Figure 1.

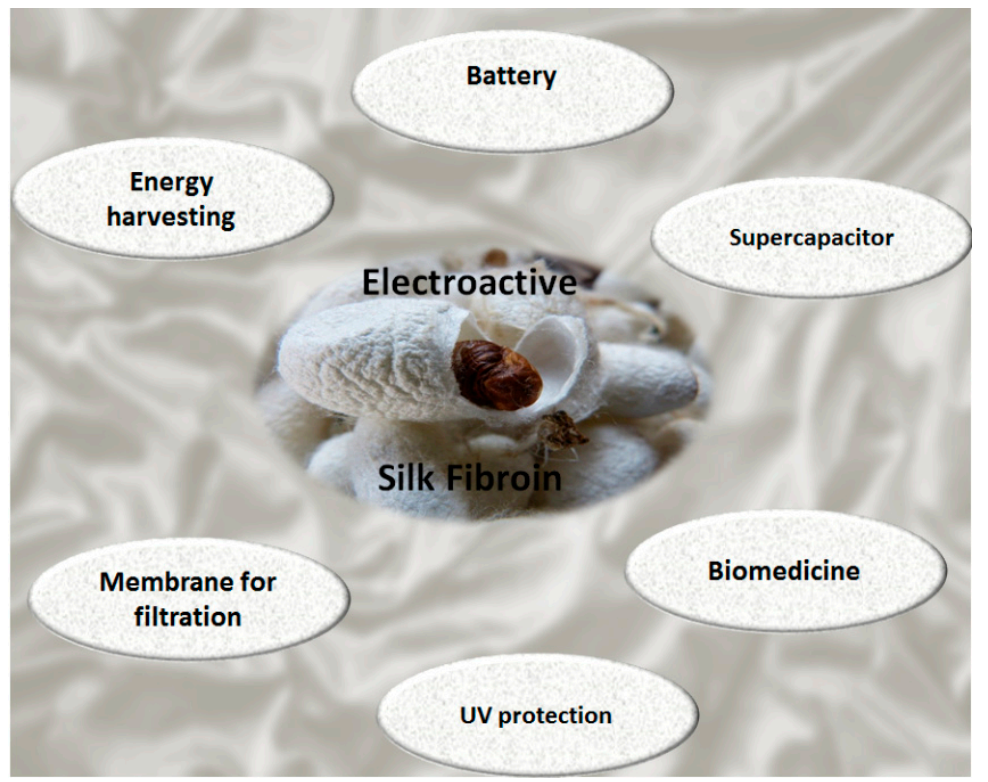

Figure 1. Applications of electroactive silk fibroin in different areas.

As shown, the use of electroactive silk fiber-based materials has been considered for energy harvesting/storage and favors applications in wearable/implantable devices. 


\section{Energy Harvesting and Storage in SF-Based Systems}

\subsection{Wearable Devices}

\subsubsection{Energy Storage Solutions}

The use of silk fabric as a template for wearable devices has been intensively reported in the literature as an important source for the production of highly efficient assemblies of electrodes. A ypical advantage for pristine samples (silk cocoons) refers to the abundance of nitrogen content and a rich porous structure that can be directly converted into hierarchical porous nitrogen-doped carbon nanosheets. The nitrogen ensures fast and reversible surface redox reactions [26] (improved pseudocapacitance) while the hierarchical porous structure offers adequate pore size distribution via rich distribution of pathways for transportation and penetration of electrolyte ions.

Different strategies have been conducted to reach these desirable conditions: the direct carbonization of silk cocoons and silk fibers followed by activation with different chemicals results in the production of a material with superior pseudocapacitive response [27-33]. As an alternative to the activation by $\mathrm{KOH}$, the simultaneous carbonization and activation with $\mathrm{ZnCl}_{2}$ and $\mathrm{FeCl}_{3}$ result in carbon nanosheets [34], while strategies of combined carbonization with different additives produce CNT/silk structures [35] for use as electrodes of supercapacitors.

The incorporation of hierarchical structures in wearable devices has been reinforced by the carbonization of natural silk fabric, followed by the deposition of MXene $\left(\mathrm{Ti}_{3} \mathrm{C}_{2} \mathrm{~T}_{\mathrm{x}}\right)$, which results in an adhesive coating to be incorporated in textiles, offering the characteristics of an electrically conductive flexible textile electrode [36] with potential for use as battery anode or supercapacitor electrodes [37].

Alternative strategies refer to the mutual carbonization of silk fibers and additives, such as graphene [38] for the following step of the coating of carbonized species with pseudocapacitive materials. The deposition of polypyrrole on carbonized silk fabric circumvents the typical drawback of pure conducting polymers-based supports relative to the self-aggregation; the polymerization on hierarchically interconnected structures favors the uniform growth of polymeric structures [39].

Beyond the typical procedure involving the carbonization of silk cocoons and silk fibers, the chemical modification of silk fabrics represents another important strategy to incorporate electrochemical properties without affecting the mechanical properties of the support. The most common procedure regards to the graphene oxide deposition on fibers to incorporate electrochemical properties of the modified filler. This process of impregnation can be established by spray coating of graphene oxide on fibers [40-42], filtration method [43], by the development of graphene oxide-based hydrogel [44] and flash freezing/lyophilization for the production of carbon aerogels [42] that are applied in the following step of reduction into reduced graphene oxide (rGO). This process can be controlled by the use of pattern photoresist (that act as a stencil) that protects regions against the reduction of material and can be applied in the production of patterns (electrodes of rGO) in microsupercapacitor prototypes [43].

The production of ternary composites on SF templates from successive incorporation of additives represents another successful strategy that associates the outstanding conductivity and large pseudocapacitance with improvement in the cycling performance of the Electrical Double Layer Capacitance (EDLC) from additives to resulting devices. For this, hierarchical deposition of multiwalled carbon nanotubes (by drop coating) has been followed by the growth of a pseudocapacitive wrapping layer of poly(3,4-ethylene dioxy-thiophene)-poly(styrene sulfonat: PEDOT: PSS [45], polypyrrole [45] and polyaniline [46] or reduced graphene oxide/polyaniline (rGO/PANI) composites [47] on silk fibers that preserve the good mechanical properties of the fibers incorporating the high conductivity level of the conducting polymers.

However, the conventional process for the production of silk fiber-based electrodes refers to the traditional assembly of pseudocapacitive/EDLC layers on metallic current collectors. For this, the deposition of gold and silver nanoparticles [48-50] represents an important strategy to improve the 
electrical properties of modified fibers that act as current collectors for electrodes of supercapacitors. Despite the higher cost for metallic treatment (growth/deposition) for the following step of chemical modification (pseudocapacitance incorporation), this process affects the overall resistance of electrodes and the corresponding electrochemical response of devices. Table 1 summarizes the most promising results for corresponding experimental systems, ordered from decreasing values of energy density, the most critical parameter in supercapacitors.

Table 1. Comparison of performance for different silk fiber-based supercapacitors in terms of energy and power density, specific capacitance and capacitance retention.

\begin{tabular}{|c|c|c|c|c|}
\hline Materials & $\begin{array}{c}\text { Energy Density/ } \\
\text { Power Density }\end{array}$ & $\begin{array}{c}\text { Specific } \\
\text { Capacitance }\end{array}$ & $\begin{array}{l}\text { Capacitance } \\
\text { Retention }\end{array}$ & Reference \\
\hline $\begin{array}{l}\text { Porous carbon obtained from } \\
\text { silkworm excrement at700 }{ }^{\circ} \mathrm{C}\end{array}$ & $\begin{array}{c}138.4 \mathrm{Wh} / \mathrm{kg} \\
495.9 \mathrm{~W} / \mathrm{kg}\end{array}$ & $\begin{array}{l}378.5 \mathrm{~F} / \mathrm{g} \\
(0.5 \mathrm{~A} / \mathrm{g})\end{array}$ & $\begin{array}{c}66.10 \% \\
\text { (9000 cycles) }\end{array}$ & [51] \\
\hline $\begin{array}{c}\text { Nitrogen-Doped } \\
\text { Carbon Nanosheets Derived from Silk }\end{array}$ & $\begin{array}{c}102 \mathrm{Wh} / \mathrm{kg} \\
-\end{array}$ & $242 \mathrm{~F} / \mathrm{g}$ & $\begin{array}{c}91 \% \\
(10,000 \text { cycles })\end{array}$ & [37] \\
\hline $\begin{array}{l}\text { Silk proteins and graphene oxide } \\
\text { carbon aerogels }\end{array}$ & $\begin{array}{l}63 \mathrm{Wh} / \mathrm{kg} \\
20 \mathrm{~kW} / \mathrm{kg}\end{array}$ & $298 \mathrm{~F} / \mathrm{g}$ & $\begin{array}{c}92.1 \% \\
\text { (5000 cycles) }\end{array}$ & [42] \\
\hline $\begin{array}{c}\mathrm{NiCo}_{2} \mathrm{~S}_{4} \text { nanotubes templated by } \\
\text { natural silk }\end{array}$ & $\begin{array}{l}52.34 \mathrm{Wh} / \mathrm{kg} \\
2206.37 \mathrm{~W} / \mathrm{kg}\end{array}$ & $\begin{array}{l}158.89 \mathrm{~F} / \mathrm{g} \\
(1 \mathrm{~A} / \mathrm{g})\end{array}$ & $\begin{array}{c}85.65 \% \\
(3000 \text { cycles at } 10 \mathrm{~A} / \mathrm{g})\end{array}$ & [52] \\
\hline $\begin{array}{l}\text { Poly(3,4-ethylenedioxythiophene)/gold } \\
\text { coated silk fiber (PEDOT-GSFs10) }\end{array}$ & $\begin{array}{l}44 \mathrm{Wh} / \mathrm{kg} \\
2458 \mathrm{~W} / \mathrm{kg}\end{array}$ & $500 \mathrm{~F} / \mathrm{g}$ & $\begin{array}{c}80 \% \\
(10,000 \text { cycles })\end{array}$ & [49] \\
\hline $\begin{array}{l}\text { Nitrogen-doped porous carbon } \\
\text { activated at } 700{ }^{\circ} \mathrm{C}\end{array}$ & $\begin{array}{c}33.6 \mathrm{Wh} / \mathrm{kg} \\
-\end{array}$ & - & - & [27] \\
\hline $\begin{array}{c}\text { Co-doped reduced graphene } \\
\text { (co-rGO)-silk fibroin composite film }\end{array}$ & $\begin{array}{l}28.31 \mathrm{Wh} / \mathrm{kg} \\
78.24 \mathrm{~kW} / \mathrm{kg}\end{array}$ & $\begin{array}{l}104 \mathrm{~F} / \mathrm{g} \\
(0.5 \mathrm{~A} / \mathrm{g})\end{array}$ & $\begin{array}{c}89 \% \\
(10,000 \text { cycles })\end{array}$ & [41] \\
\hline $\begin{array}{l}\text { Graphene/Silk Fibroin Based Carbon } \\
\text { Nanocomposite }\end{array}$ & $\begin{array}{l}22.8 \mathrm{Wh} / \mathrm{kg} \\
200 \mathrm{~W} / \mathrm{kg}\end{array}$ & $\begin{array}{l}230 \mathrm{~F} / \mathrm{g} \\
(1 \mathrm{~A} / \mathrm{g})\end{array}$ & - & [38] \\
\hline $\begin{array}{l}\text { Three dimensional (3D) } \\
\text { heteroatom-doped active carbon }\end{array}$ & $\begin{array}{l}17.2 \mathrm{Wh} / \mathrm{kg} \\
207 \mathrm{~W} / \mathrm{kg}\end{array}$ & $\begin{array}{c}48.6 \mathrm{~F} / \mathrm{g} \\
\left(0.7 \mathrm{~mA} / \mathrm{cm}^{2}\right)\end{array}$ & $\begin{array}{c}116 \% \\
(10,000 \text { cycles })\end{array}$ & [30] \\
\hline Carbonized silk at $850^{\circ} \mathrm{C}$ & $\begin{array}{l}14.33 \mathrm{Wh} / \mathrm{kg} \\
251 \mathrm{~W} / \mathrm{kg}\end{array}$ & $\begin{array}{l}178 \mathrm{~F} / \mathrm{g} \\
(0.5 \mathrm{~A} / \mathrm{g})\end{array}$ & - & [34] \\
\hline $\begin{array}{l}\text { Flexible all-solid hollow graphene } \\
\text { fiber supercapacitor }\end{array}$ & $\begin{array}{c}2.64 \mathrm{Wh} / \mathrm{kg} \\
-\end{array}$ & $\begin{array}{l}76.1 \mathrm{~F} / \mathrm{g} \\
(1 \mathrm{~A} / \mathrm{g})\end{array}$ & $\begin{array}{c}90.50 \% \\
(2000 \text { cycles })\end{array}$ & [40] \\
\hline Polypyrrole/carbonized silk fabric & $\begin{array}{c}6.88 \mathrm{mWh} / \mathrm{cm}^{3} \\
0.04 \mathrm{~W} / \mathrm{cm}^{3}\end{array}$ & $\begin{array}{c}666.78 \mathrm{mF} / \mathrm{cm}^{2} \\
\left(2 \mathrm{~mA} / \mathrm{cm}^{2}\right)\end{array}$ & $\begin{array}{c}47 \% \\
\text { (500 cycles) }\end{array}$ & [39] \\
\hline
\end{tabular}

As previously described, a very interesting constitutive aspect of silk derivatives is the abundant nitrogen content. The good pseudocapacitive contribution of nitrogen-doped structures combined with the hierarchical and pore-rich structure of carbon derived materials confirms the carbonization of silk derivatives as one of the most promising strategies to reach outstanding performance in supercapacitors. As observed in the first line of Table 1, an energy density in the order of $138.4 \mathrm{Wh} / \mathrm{kg}$ is observed for nitrogen-rich honey-comb-like hierarchical structure produced by the calcination at $200{ }^{\circ} \mathrm{C}$ of silkworm excrements [51]. A corresponding process of activation and graphitization of biomass-derived natural silk results in a porous material with outstanding surface area $\left(2494 \mathrm{~m}^{2} / \mathrm{g}\right)$ with good performance in energy storage (102 Wh/kg) and high capacitance retention (91\% after 10,000 cycles) [37].

Alternatively to the carbonization of silk-derived compounds, the modification of regenerated silk fibroins results in carbon aerogels with graphene oxide $(63 \mathrm{Wh} / \mathrm{kg})$ [42] while hydrothermal sulfurization results in composites with $\mathrm{NiCO}_{2} \mathrm{~S}_{4}$ with good performance in terms of energy density $(52.34 \mathrm{Wh} / \mathrm{kg})$ [52]. Despite these promising results for the thermal treatment of silk fibers, the chemical modification of the pristine fibers remains a promising strategy to be applied in the production of coaxial structures with good electrochemical performance. For this, it is reported [49] a standard procedure in which the current collector is produced by metal deposition of gold/silver layer on 
silk fiber for the following step in which the polymeric layer of PEDOT is deposited. The resulting device presents an outstanding specific capacitance of $500 \mathrm{~F} / \mathrm{g}$. The incorporation of silk fibroin in wearable electronics has been considered a promising step toward reaching the desirable condition for sustainable implantable and wearable devices.

\subsubsection{Energy Harvesting Solutions}

The internet of things has been progressively incorporated in our daily life, with the integration of electronic equipment [53], sensors and actuators. Moreover, the incorporation of self-powered energy storage devices (lithium-ion batteries and supercapacitors) in wearable electronics is a necessary step toward the full operation of all of the devices [54]. In particular, the small size of these energy storage devices requires strategies to reach continuous charge of devices avoiding external connections. This process reinforces the requirement for the development of wearable generators that harvest energy from different sources.

Many processes have been explored to harvest energy, such as piezoelectricity [55], thermoelectricity [56], photoelectricity, electromagnetic effect and triboelectricity [57]. Based on this diversity of mechanisms, it has been progressively reported in the literature the use of different experimental systems to capture a small amount of energy from movement, heat or vibration and to convert it into electric energy directed to the electronic device. The Seebeck effect is an important mechanism that converts the gradient of temperature in a hot junction into electric energy [56]. For this, silk fibers have been coated with different materials (such as $\mathrm{Bi}_{2} \mathrm{Te}_{3}$ and $\mathrm{Sb}_{2} \mathrm{Te}_{3}$ ) in opposite sides assembled as thermoelectric columns [56].

The development of alternative thermocouples devices based on silk fibroin [8] has been observed from the deposition of Ag nanowires on silk fibers for the following step of polymerization of PEDOT: PSS in textile thermoelectric devices that convert the gradient of temperature between the body and the ambient into electricity.

More simplified assemblies based on silk cocoons explored the ability of these materials to promote the current flow of ionic charge carriers facilitated by the incorporation of adsorbed species into silk cocoon membranes disposed of between distinct electrodes [58,59], such as copper (anode) and aluminum (cathode). The incorporation of these additives can be established by direct adsorption of nanoparticles by silk fibers or by the direct administration of silver nanoparticles into the diet of the silk larvae [59].

On the other hand, an interesting process that incorporates silk fibroin into the production of nanoand micro-generators makes use of the triboelectric phenomena. The combination of electrification effect and electrostatic processes allows that energy in mechanical vibrations rotation and body motion can be harvested.

Figure 2 (reproduced from [60]) introduces a typical device-triboelectric nanogenerator (TENG) that converts SF into silk fibroin-based composite aerogel in a standard prototype composed by spacers and electrodes coated by a polytetrafluoroethylene (PTFE) layer filter paper and the silk aerogel/carbon nanofiber-silk aerogel (CNF/silk aerogel) on the opposite side acting as a triboelectric pair for the generation of energy.

Another important strategy for the effective development of silk fibroin-based devices is the alignment of the polymer chains that favor the dipole orientation. The production of electrospun silk fibroins stabilized with methanol favors applications, such as airflow; energy harvesting systems [57] that are based on the disposition of silk fibers between dimethylpolysiloxane (PDMS) layers, allowing that vibration of silk fibers and the resulting friction against PDMS films can be explored in the generation of charges on the triboelectric pairs. In common, an important property for silk fibroin structures refers to the ultra-high surface-to-volume ratio of the natural fibrillar structures that provide adequate condition to harvest energy. For comparison of different processes, Table 2 summarizes the most relevant parameters from silk-fibroin-based harvesting devices (in terms of maximum voltage, power density and the internal resistance of the power source). 

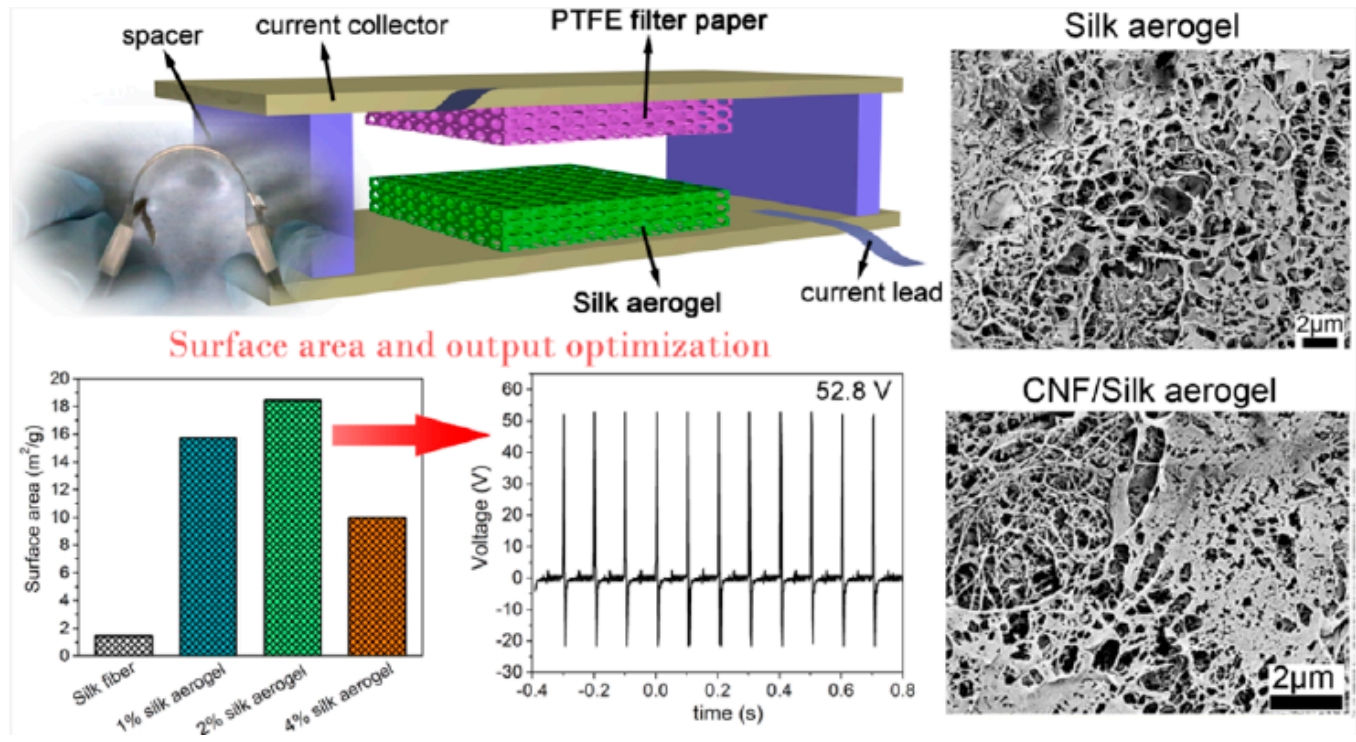

Figure 2. A schematic view of triboelectric nanogenerator (TENG) device based on silk aerogel is applied as an active layer. Reprinted with permission from [60]. Copyright (2020) American Chemical Society.

Table 2. Comparison of maximum values of current and power and the power density of different silk-based harvesting systems.

\begin{tabular}{|c|c|c|c|c|}
\hline \multirow{2}{*}{ Samples } & \multirow{2}{*}{$\begin{array}{l}\mathrm{V}_{\text {out_max }} / \\
\text { Pout_max }_{\text {oux }}\end{array}$} & \multirow{2}{*}{$\begin{array}{l}P_{\text {density }} \\
\left(W / m^{2}\right)\end{array}$} & \multirow{2}{*}{$\begin{array}{c}\text { Internal } \\
\text { Resistance }(\mathrm{M} \Omega)\end{array}$} & \multirow{2}{*}{ Ref } \\
\hline & & & & \\
\hline $\begin{array}{l}\text { Indium tin oxide (ITO) coated polyethylene } \\
\text { terephthalate(PET)/PDMS/Silk fibroin triboelectric microgenerator }\end{array}$ & $\begin{array}{c}35 \mathrm{~V} / \\
162 \mu \mathrm{W}\end{array}$ & 864 & 8 & [57] \\
\hline $\begin{array}{c}\text { TEMG } \\
\text { Silver nanowire (AgNW)/Silk fibroin TENG }\end{array}$ & $40 \mathrm{~V} /$ & 20 & 1 & {$[61]$} \\
\hline Printed Silk Fibroin -TENG & $\begin{array}{c}666 \mathrm{~V} / \\
4.21 \mathrm{~mW}\end{array}$ & 4.12 & 10 & [62] \\
\hline Silk Fibroin/PET/ITO triboelectric generator (TEG) & $\begin{array}{c}268 \mathrm{~V} / \\
1.55 \mathrm{~mW}\end{array}$ & 1.936 & 40 & {$[63]$} \\
\hline Indium tin oxide (ITO) coated polyethylene terephthalate(PET)/SF & $\begin{array}{l}260 \mathrm{~V} / \\
0.65 \mathrm{~mW}\end{array}$ & 1.615 & 30 & [64] \\
\hline Carbon nanofibers/Silk & $\begin{array}{c}11.8 \mathrm{~V} / \\
-\end{array}$ & 0.37 & $0.001-10$ & {$[60]$} \\
\hline $\begin{array}{l}\text { nascent silk nanoribbon film/regenerative silk fibroin } \\
\text { film (SNRF/RSFF) }\end{array}$ & $\begin{array}{c}41.64 \mathrm{~V} / \\
-\end{array}$ & 0.0867 & 100 & {$[65]$} \\
\hline SF/Indium tin oxide (ITO) coated polyethylene terephthalate (PET) & $218.1 \mathrm{~V} /$ & 0.068 & $0.1-100$ & [53] \\
\hline Silk/Pl/Al & - & 0.0043 & 5 & [66] \\
\hline $\begin{array}{l}\text { silk fiber/stainless steel fiber and polytetrafuoroethylene } \\
\text { fiber/stainless steel fiber }\end{array}$ & $\begin{array}{c}27 \mathrm{~V} / \\
- \\
-\end{array}$ & 0.0035 & 50 & [67] \\
\hline
\end{tabular}

The order in devices in Table 2 is established by values of power density to evaluate the performance in the harvesting of energy from different processes. In common, it is observed that superior performance is reached for triboelectric micro- (TEMG), nano- (TENG) and TEG generators. The best performance of reported devices has been observed for the SF-based TEMG system deposited on dimethylpolysiloxane/Indium tin oxide (PDMS/ITO) films applied in the airflow conversion into energy reaching power density of $864 \mathrm{~W} / \mathrm{m}^{2}$ and internal resistance of $8 \mathrm{M} \Omega$ [57]. The development of SF-based TENG devices is observed from devices that intercalate silk fibroin with silver nanowires that generate a power density of $20 \mathrm{~W} / \mathrm{m}^{2}$ from finger contact with the sensor [61]. 
As an alternative to these systems, it is reported the development of cost-effective devices from the production of interdigitated graphite electrodes coated with thin films of silk fibroin that effectively harvest the energy from movements [62]. Alternatives based on PET/ITO have been optimized by oxygen plasma treatment with RF plasma to create a good interaction level with silk fibroin triboelectric pairs [63].

\subsection{Implantable Devices}

\section{Energy Storage Solutions}

Implantable bioelectronic devices are important components for the development of medicine [61]. In common, these systems rely on superior electrical performance to be applied in the storage of energy.

On the other hand, the high conductivity and intrinsic cytocompatibility of chemically modified silk fibroins open possibilities for the development of nerve guide conduits for applications in nerve injuries [68] produced from the double coating of graphene oxide/polypyrrole on silk fibroin, associating the superior mechanical properties of graphene oxide and the outstanding electroactive response of polypyrrole. Blending with graphene oxide offers adequate combination for the production of scaffolds $[4,12]$ while the incorporation of polypyrrole has been also directed applied to the production of biocompatible/biodegradable batteries (acting as a cathode) coupled with bioresorbable Mg alloy immersed in a saline electrolyte (PBS) [69]. Applications in wound dressing are also favored by the incorporation (under high-intensity ultrasound) of $\mathrm{ZnO}$ nanoparticles in the hydrogel-grafted silk fibroins [70] while ultraviolet protection is favored by the incorporation of $\mathrm{TiO}_{2} / \mathrm{La}$ (III) nanoparticles composites in silk fabrics [19].

The assembly of silk fibroins in hybrid membranes results in a negatively charged surface with nanochannels for ion transportation; these membranes are applied as prototypes for osmotic energy conversion systems [71].

In particular, biodegradable separators are critical components for active implantable medical devices (AIMDs) that presented important advances to be considered as temporary devices. In this case, it is expected the disintegration or resorption of devices by the body in a process that bioabsorbable batteries must preserve the electrical functionality of the AIMDs under degradation. The use of as-collected Bombyx mori silkworm cocoons has been reported in the literature as a green strategy to produce separators for batteries $[33,72,73]$.

The optimization in the performance of silk fibroins was reached with changes in morphology, from the production of SF-membrane films, SF-sponges and SF-electrospun membranes immersed in commercial ionic liquids [74]. Other strategies are based on the control of the pore size of SF-based systems that have a direct influence on electrolyte uptake [75]. It is reached by the etching on nanofibrils from the direct action of oxygen and nitrogen plasma treatment at different exposure times.

In particular, the development of silk-fibroin-based on-board biodegradable power sources has been successfully applied in transient implantable medical bionics [76] that can be applied in the detection and actuation of vital signals into the human body [69]. The use is directed to the control of drug delivery systems and cardiovascular stimulus, in which electrical stimulus and biodegradability/biocompatibility are mutually required [69]. To reach these properties, it is necessary to eliminate the toxicity of some components of traditional batteries, controlling the lifetime of batteries and increasing the power density of the resulting devices.

For this, the association of silk fibroin and polypyrrole as a cathode and $\mathrm{Mg}$ bioresorbable alloy as anode immersed in phosphate-buffered saline electrolyte simulates the adequate incorporation of a biodegradable device that explores the body fluid as an electrolyte, allowing that device can be absorbed by the body [69]. An alternative that has been applied in the control of the overall consumption of the device has been reported in [76], in which biodegradable film of SF encapsulates the device prepared from a combination of silk fibroin and choline nitrate and a biodegradable thin 
film of magnesium. The coating layer of SF is responsible for the control in the lifetime of the overall device [76].

The performance of batteries based on silk fibroin as fillers/separators is summarized in Table 3.

Table 3. Comparison of efficiency parameters for silk fibroin-based batteries.

\begin{tabular}{|c|c|c|}
\hline Material & Discharge Capacity & Reference \\
\hline $\mathrm{MoS}_{2} /$ Carbonized Silk electrode & $2895 \mathrm{mAh} / \mathrm{g}$ & [77] \\
\hline Hierarchical porous nitrogen doped carbon nanosheets & $1865 \mathrm{mAh} / \mathrm{g}$ & [37] \\
\hline $\mathrm{ZnCo}_{2} \mathrm{O}_{4}$ nanocubes-CSF & $778 \mathrm{mAh} / \mathrm{g}$ & [78] \\
\hline Silk derived substrates for $\mathrm{Zn}$-Air batteries & $614.7 \mathrm{mAh} / \mathrm{g}$ & [79] \\
\hline Nano porous carbon nanosheets & $383 \mathrm{mAh} / \mathrm{g}$ & [80] \\
\hline $\begin{array}{l}\text { Battery separators based on silk fibroin sponges prepared } \\
\text { by lyophilization }\end{array}$ & $126 \mathrm{mAh} / \mathrm{g}$ & [74] \\
\hline Silk fibroin separator membranes for lithium-ion batteries & $131.3 \mathrm{mAh} / \mathrm{g}$ & [75] \\
\hline $\begin{array}{c}\text { Bombyx mori cocoon separators for high-performance and sustainable } \\
\text { lithium-ion batteries }\end{array}$ & $96.7 \mathrm{mAh} / \mathrm{g}$ & [33] \\
\hline Bombyx mori silkworm cocoons separators for lithium ( $\mathrm{Li}$ )-ion batteries & $86 \mathrm{mAh} / \mathrm{g}$ & [72] \\
\hline Mg-Air Biobatteries of silk fiber - polypyrrole(SF-PPy) Film & $3.79 \mathrm{mAh} / \mathrm{cm}^{2}$ & [69] \\
\hline
\end{tabular}

In terms of performance (measured from discharge capacity), an important aspect to be considered for batteries refers to the porosity, degree of conductivity and flexibility of the electrodes. The poor electroactive properties of silk fabrics have been circumvented by two different strategies: the carbonization of the structure or the incorporation of additives. The best response for lithium-ion batteries based on silk fibers (applied as constitutive media for battery anodes) was reached from an initial step of carbonization followed by the growth of hierarchical structures [37], such as the in situ growth of molybdenum disulfide (vertically oriented on carbonized silk fibers) [77], or by the growth of $\mathrm{ZnCo}_{2} \mathrm{O}_{4}$ in 3D conductive networks [78].

The thermal treatment of SF with the incorporation of additives has been reported in [79], in which air cathode-based Zn-Air battery makes use of a nitrogen-doped nanocarbon structure prepared from the pyrolysis of porous Ketjenblack impregnated with silk fibers. The scheme of preparation and final device is shown in Figure 3 (reproduced from [79]).
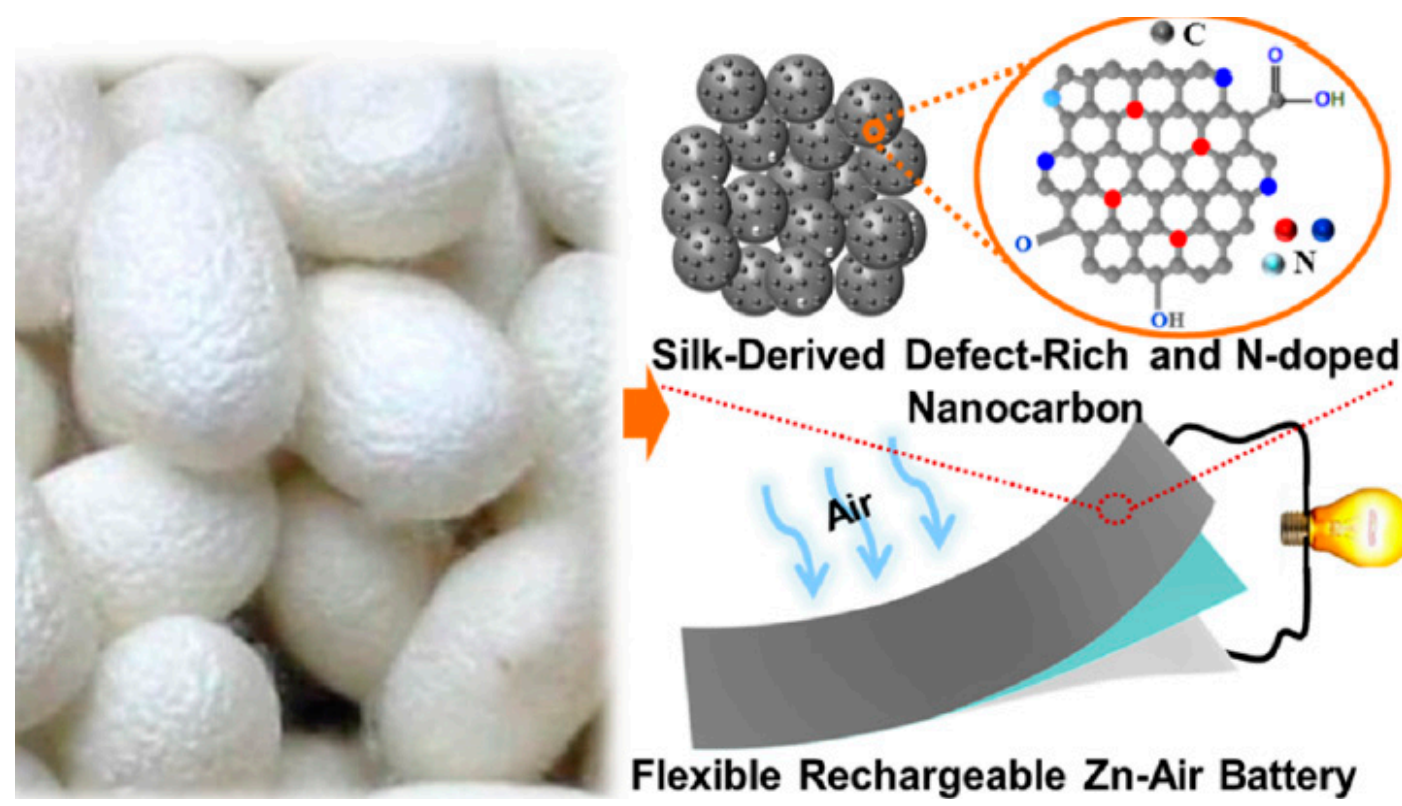

Silk-Derived Defect-Rich and N-doped

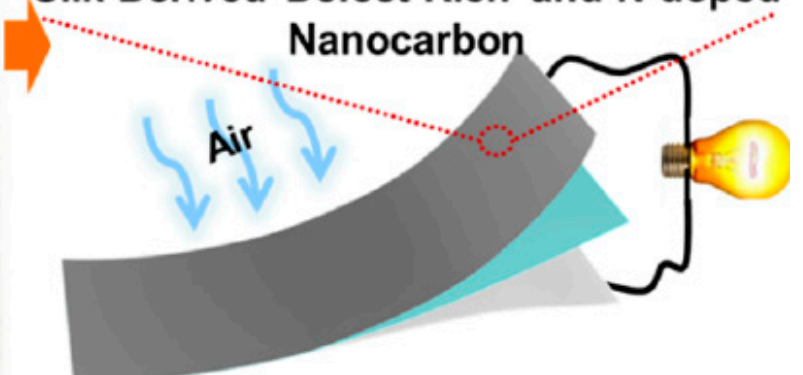

Flexible Rechargeable Zn-Air Battery

Figure 3. Schematic view of Zn Air battery-based silk fibroin. Reprinted with permission from Ref. [79]. Copyright (2019) American Chemical Society. 
The N-doped nanocarbon structures that result from pyrolysis are applied by drop-casting onto carbon cloth that acts as an air cathode for Zn-Air batteries, reaching a discharging capacity of $614.7 \mathrm{mAh} / \mathrm{g}$. Based on these results, the best performance for SF-based batteries is reached for porous batteries based on carbonized silk fibroin making use of lithium-ion due to the superior properties of ions and porosity of the matrix. Despite the low performance for biobattery based on silk fibers, the most important property for this system refers to the negligible toxicity/good biocompatibility/degradability of the resulting devices, characterizing an important topic to be investigated in SF-based batteries.

\section{Discussion and Perspectives}

The incorporation of green electronics concepts and the development of more effective energy storage devices introduce ancient fibers as promising templates for chemical modification and the following implementation in wearable/implantable devices. Batteries are the most common energy supplier components, due to the intrinsic high performance in terms of energy density, assembled by the conventional disposition of two electrodes (anode and cathode) and separated by a membrane (separator) that acts as a physical barrier to avoid short circuit and to provide adequate ionic transportation: while the anode potential affects the cell voltage, the nature of the cathode determines the battery capacity [75]. The most common experimental systems are based on lithium-ion based batteries (LIBs) that introduce advantages on conventional acid and nickel-metal hybrid batteries $(\mathrm{NiMH})$ in terms of Coulombic efficiency, energy density, memory effects and open-circuit voltage. Despite the relevance of electrodes and electrolyte, a critical component to be considered in the overall device refers to the separator. In the conventional structure, these polymeric membranes are soaked into an electrolyte being critical factors for the definition of cost, cycle life, reliability and safety of the resulting battery [33]. Silk fibroin-based membranes are promising candidates for use as environmentally friendly separators of batteries, with particular interest for biobatteries with controllable consumption by the body-minimizing additional surgeries for battery removal. The production of hybrid devices considering natural material as separators and electrodes represents an important step in the direction to reach an all-green device. For this, the important strategy reported in [76] (from the encapsulation of device with SF layer) can be explored in implantable bio-based applications while the integration of electrodes/separators of SF can be conveniently addressed to reach requirements for flexibility and electrochemical requisites for the development of green batteries.

On the other hand, the use of SF in supercapacitors for wearables has been focused on the balanced contribution of EDLC and pseudocapacitance terms, reinforcing the combination of highly porous structures and metal oxide/conducting polymers as promising supports for outstanding electrochemical response systems.

In general, the good specific capacitance (C) for pseudocapacitance-based materials is associated with a limited voltage window $(\mathrm{V})$, with direct implication on energy density $\left(E=C^{2} / 2\right)$. As a consequence, the improvement in the energy density of supercapacitors has been considered from the increase in the voltage windows (from the production of asymmetric supercapacitors): $\mathrm{V}>1 \mathrm{~V}$ and by the combined action of pseudocapacitance and EDLC response [81].

The most-reported strategy to reach good performance in SF-based supercapacitors has been the production of nitrogen-doped highly porous structures prepared by carbonization of silk fibers for the following step of use as conductive ink for application in textiles (serving as electrodes). However, the coating of fibers with conducting polymer layers, metal oxide nanoparticles and metal nanowires has been considered a promising chemical procedure that preserves the structure of the material (reducing the costs of thermal treatment), opening the possibility of production of asymmetric devices with higher energy density (broad window voltage) and easy integration with textiles in wearable devices. Alternatives to produce highly porous structures (without the carbonization of silk) appears with the processing of regenerated silk firoin in electrospun fibers, in which is possible to control the incorporation degree of and additives and alignment of fibers. This process favors not only the 
production of more conductive electrodes, but also the effective charge generation in fibers surface applied as an active element in triboelectric generator systems.

Figure 4 summarizes the most common procedures (chemical modification, electrospinning technique and carbonization) that are applied in silk derivatives to reach desirable properties for use as a separator, active layer or electrodes for energy harvesting systems, supercapacitors and batteries.

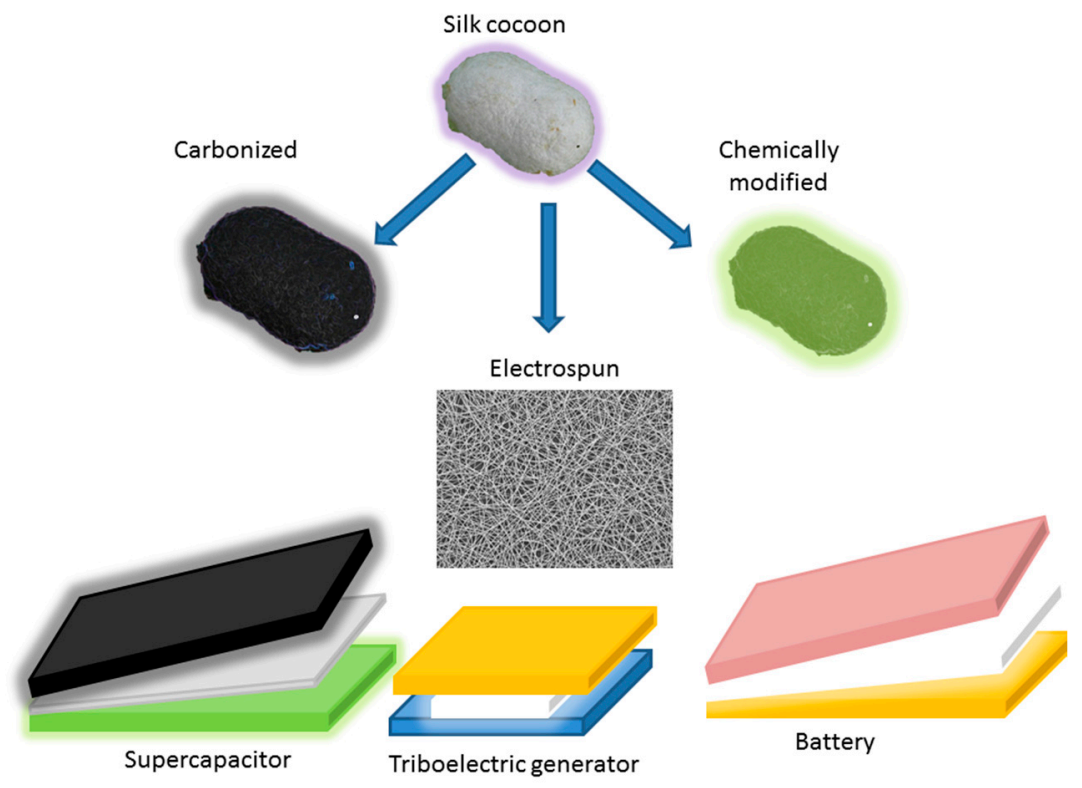

Figure 4. Standard modifications (carbonization, production of electrospun fibers from regenerated material and chemical deposition) and application as electrodes for supercapacitors and separator for triboelectric generators and batteries/biobatteries for silk fibroin derivatives.

Based on these strategies, important advances have been observed in devices such as Mg-Air-based biobatteries, separators for conventional Li-ion batteries, wearable supercapacitors and active layer for energy harvesting systems.

\section{Conclusions}

Green electronics are potentially favored by the incorporation of natural materials in the substitution of scarce and toxic components. The incorporation of silk fibroin in energy storage/harvesting devices follows different strategies: high energy-density-based applications (production of lithium-ion batteries) explore the nitrogen-rich hierarchical structure that results from carbonization while the biomedical application explores all of biocompatibility/biodegradability offered by silk fibroin derivatives applied as electrodes (acquiring electroconductive properties) or as separator/active membrane for harvesting energy. Despite current advances in the hierarchical structures produced from the carbonization of silk fibers, these results confirm a clear tendency for the use of pristine SF as support for chemical modification (reinforcement in mechanical/electrical properties), exploring a more complete range of possibilities in which new biomedical and implantable devices are favored by a flexible, biocompatible and cost-effective of silk fibroin. These aspects confirm this natural product as an important building block for green and self-powered electronic devices with superior performance in degradable, implantable and wearable systems. The barrier for an all-SF device can be considered an important step that integrates applications of wearable and implantable silk-based devices.

Author Contributions: Conceptualization: H.P.d.O.; Investigation: M.C.A.d.O., R.M.A.P.L.; Funding acquisition: H.P.d.O.; Supervision: H.P.d.O.; Writing—original draft: H.P.d.O., M.C.A.d.O., R.M.A.P.L.; Writing-review and editing: H.P.d.O. All authors have read and agreed to the published version of the manuscript. 
Funding: This work was supported by Brazilian agencies CNPq and CAPES.

Conflicts of Interest: The authors declare no conflict of interest.

\section{References}

1. Zhu, B.; Wang, H.; Leow, W.R.; Cai, Y.; Loh, X.J.; Han, M.Y.; Chen, X. Silk fibroin for flexible electronic devices. Adv. Mater. 2016, 28, 4250-4265. [CrossRef] [PubMed]

2. López Barreiro, D.; Martín-Moldes, Z.; Yeo, J.; Shen, S.; Hawker, M.J.; Martin-Martinez, F.J.; Kaplan, D.L.; Buehler, M.J. Conductive Silk-based composites using biobased carbon materials. Adv. Mater. 2019, 31. [CrossRef] [PubMed]

3. Irimia-Vladu, M. “Green" electronics: Biodegradable and biocompatible materials and devices for sustainable future. Chem. Soc. Rev. 2014, 43, 588-610. [CrossRef] [PubMed]

4. Zhang, C.; Fan, S.; Shao, H.; Hu, X.; Zhu, B.; Zhang, Y. Graphene Trapped silk scaffolds integrate high conductivity and stability. Carbon N. Y. 2019, 148, 16-27. [CrossRef]

5. Wang, C.; Xia, K.; Zhang, Y.; Kaplan, D.L. Silk-based advanced materials for soft electronics. Acc. Chem. Res. 2019, 52, 2916-2927. [CrossRef] [PubMed]

6. Lu, Z.; Mao, C.; Zhang, H. Highly conductive graphene-coated silk fabricated via a repeated coating-reduction approach. J. Mater. Chem. C 2015, 3, 4265-4268. [CrossRef]

7. Lima, R.M.A.P.; Alcaraz-Espinoza, J.J.; Da Silva, F.A.G.; De Oliveira, H.P. Multifunctional wearable electronic textiles using cotton fibers with polypyrrole and carbon nanotubes. ACS Appl. Mater. Interfaces 2018, 10, 13783-13795. [CrossRef] [PubMed]

8. Hwang, B.; Lund, A.; Tian, Y.; Darabi, S.; Darabi, S.; Müller, C.; Müller, C. Machine-washable conductive silk yarns with a composite coating of Ag nanowires and PEDOT:PSS. ACS Appl. Mater. Interfaces 2020, 12, 27537-27544. [CrossRef]

9. Ye, C.; Ren, J.; Wang, Y.; Zhang, W.; Qian, C.; Han, J.; Zhang, C.; Jin, K.; Buehler, M.J.; Kaplan, D.L.; et al. Design and fabrication of silk templated electronic yarns and applications in multifunctional textiles. Matter 2019, 1, 1411-1425. [CrossRef]

10. Huang, L.; Li, C.; Yuan, W.; Shi, G. Strong composite films with layered structures prepared by casting silk fibroin-graphene oxide hydrogels. Nanoscale 2013, 5, 3780-3786. [CrossRef]

11. Xia, Y.; Yun, L. Fabrication and properties of conductive conjugated polymers/silk fibroin composite fibers. Compos. Sci. Technol. 2008, 68, 1471-1479. [CrossRef]

12. Wang, S.-D.; Ma, Q.; Wang, K.; Ma, P.-B. Strong and biocompatible three-dimensional porous silk fibroin/graphene oxide scaffold prepared by phase separation. Int. J. Biol. Macromol. 2018, 111, 237-246. [CrossRef] [PubMed]

13. Yang, J.; Luo, J.; Liu, H.; Shi, L.; Welch, K.; Wang, Z.; Strømme, M. Electrochemically active, compressible, and conducting silk fibroin hydrogels. Ind. Eng. Chem. Res. 2020, 59, 9310-9317. [CrossRef]

14. Romero, I.S.; Schurr, M.L.; Lally, J.V.; Kotlik, M.Z.; Murphy, A.R. Enhancing the interface in silk-polypyrrole composites through chemical modification of silk fibroin. ACS Appl. Mater. Interfaces 2013, 5, 553-564. [CrossRef] [PubMed]

15. Malhotra, U.; Maity, S.; Chatterjee, A. Polypyrrole-silk electro-conductive composite fabric by in situ chemical polymerization. J. Appl. Polym. Sci. 2015, 132. [CrossRef]

16. Cucchi, I.; Boschi, A.; Arosio, C.; Bertini, F.; Freddi, G.; Catellani, M. Bio-based conductive composites: Preparation and properties of polypyrrole (PPy)-coated silk fabrics. Synth. Met. 2009, 159, $246-253$. [CrossRef]

17. Padma Priya, S.; Rai, S.K. Studies on the mechanical performance of PMMA toughened epoxy-silk and PC toughened epoxy-silk fabric composites. J. Reinf. Plast. Compos. 2006, 25, 33-41. [CrossRef]

18. Padma Priya, S.; Rai, S.K. Impact, compression, density, void content, and weight reduction studies on waste silk fabric/epoxy composites. J. Reinf. Plast. Compos. 2005, 24, 1605-1610. [CrossRef]

19. Shudong Wang, Y.Z. Preparation of the silk fabric with ultraviolet protection and yellowing resistance using $\mathrm{TiO} 2 / \mathrm{La}(\mathrm{III})$ composite nanoparticles. Fibers Polym. 2014, 15, 1129-1136. [CrossRef]

20. Wang, Q.; Yan, S.; Han, G.; Li, X.; You, R.; Zhang, Q.; Li, M.; Kaplan, D.L. Facile production of natural silk nanofibers for electronic device applications. Compos. Sci. Technol. 2020, 187, 107950. [CrossRef] 
21. Cao, J.; Wang, C. Multifunctional surface modification of silk fabric via graphene oxide repeatedly coating and chemical reduction method. Appl. Surf. Sci. 2017, 405, 380-388. [CrossRef]

22. Wang, Q.; Wang, C.; Zhang, M.; Jian, M.; Zhang, Y. Feeding single-walled carbon nanotubes or graphene to silkworms for reinforced silk fibers. Nano Lett. 2016, 16, 6695-6700. [CrossRef] [PubMed]

23. Han, K.I.; Kim, S.; Lee, I.G.; Kim, J.P.; Kim, J.H.; Hong, S.W.; Cho, B.J.; Hwang, W.S. Compliment graphene oxide coating on silk fiber surface via electrostatic force for capacitive humidity sensor applications. Sensors 2017, 17, 407. [CrossRef] [PubMed]

24. Izyan Syazana Mohd Yusoff, N.; Uzir Wahit, M.; Jaafar, J.; Wong, T.-W. Characterization of graphene-silk fibroin composites film. Mater. Today Proc. 2018, 5, 21853-21860. [CrossRef]

25. Hu, X.; Li, J.; Bai, Y. Fabrication of high strength graphene/regenerated silk fibroin composite fibers by wet spinning. Mater. Lett. 2017, 194, 224-226. [CrossRef]

26. Sahu, V.; Grover, S.; Tulachan, B.; Sharma, M.; Srivastava, G.; Roy, M.; Saxena, M.; Sethy, N.; Bhargava, K.; Philip, D.; et al. Heavily nitrogen doped, graphene supercapacitor from silk cocoon. Electrochim. Acta 2015, 160, 244-253. [CrossRef]

27. Long, C.; Zhuang, J.; Xiao, Y.; Zheng, M.; Hu, H.; Dong, H.; Lei, B.; Zhang, H.; Liu, Y. Nitrogen-doped porous carbon with an ultrahigh specific surface area for superior performance supercapacitors. J. Power Sources 2016, 310, 145-153. [CrossRef]

28. Song, P.; Shen, X.; He, W.; Kong, L.; He, X.; Ji, Z.; Yuan, A.; Zhu, G.; Li, N. Protein-derived nitrogen-doped hierarchically porous carbon as electrode material for supercapacitors. J. Mater. Sci. Mater. Electron. 2018, 29, 2206-12215. [CrossRef]

29. Liu, R.; Pan, L.; Wan, L.; Wu, D. An evaporation-induced tri-consistent assembly route towards nitrogen-doped carbon microfibers with ordered mesopores for high performance supercapacitors. Phys. Chem. Chem. Phys. 2015, 17, 4724-4729. [CrossRef]

30. Zou, B.X.; Gao, Y.; Liu, B.; Yu, Y.; Lu, Y. Three dimensional heteroatom-doped carbon composite film for flexible solid-state supercapacitors. RSC Adv. 2016, 6, 4483-4489. [CrossRef]

31. Ma, D.L.; Ma, Y.; Chen, Z.W.; Hu, A.M. A silk fabric derived carbon fibre net for transparent capacitive touch pads and all-solid supercapacitors. J. Mater. Chem. A 2017, 5, 20608-20614. [CrossRef]

32. Yun, Y.S.; Cho, S.Y.; Shim, J.; Kim, B.H.; Chang, S.J.; Baek, S.J.; Huh, Y.S.; Tak, Y.; Park, Y.W.; Park, S.; et al. Microporous carbon nanoplates from regenerated silk proteins for supercapacitors. Adv. Mater. 2013, 25, 1993-1998. [CrossRef]

33. Pereira, R.F.P.; Gonçalves, R.; Gonçalves, H.M.R.; Correia, D.M.; Costa, C.M.; Silva, M.M.; Lanceros-Méndez, S.; de Zea Bermudez, V. Plasma-Treated bombyx mori cocoon separators for high-performance and sustainable lithium-ion batteries. Mater. Today Sustain. 2020, 9, 100041. [CrossRef]

34. Zhang, L.; Meng, Z.; Qi, Q.; Yan, W.; Lin, N.; Liu, X.Y. Aqueous supercapacitors based on carbonized silk electrodes. RSC Adv. 2018, 8, 22146-22153. [CrossRef]

35. Yang, M.; Zeng, X.; Zhang, X.; Yang, Z. 3D Silk fibroin/carbon nanotube array composite matrix for flexible solid-state supercapacitors. New J. Chem. 2020, 44, 6575-6582. [CrossRef]

36. Hu, M.; Hu, T.; Cheng, R.; Yang, J.; Cui, C.; Zhang, C.; Wang, X. MXene-coated silk-derived carbon cloth toward flexible electrode for supercapacitor application. J. Energy Chem. 2018, 27, 161-166. [CrossRef]

37. Hou, J.; Cao, C.; Idrees, F.; Ma, X. Hierarchical porous nitrogen-doped carbon nanosheets derived from silk for ultrahigh-capacity battery anodes and supercapacitors. ACS Nano 2015, 9, 2556-2564. [CrossRef] [PubMed]

38. Wang, Y.; Song, Y.; Wang, Y.; Chen, X.; Xia, Y.; Shao, Z. Graphene/silk fibroin based carbon nanocomposites for high performance supercapacitors. J. Mater. Chem. A 2015, 3, 773-781. [CrossRef]

39. Li, X.; Sun, C.; Cai, Z.; Ge, F. High-performance all-solid-state supercapacitor derived from PPy coated carbonized silk fabric. Appl. Surf. Sci. 2019, 473, 967-975. [CrossRef]

40. Jiang, D.; Zhang, J.; Li, C.; Yang, W.; Liu, J. A simple and large-scale method to prepare flexible hollow graphene fibers for a high-performance all-solid fiber supercapacitor. New J. Chem. 2017, 41, 11792-11799. [CrossRef]

41. Rath, T.; Pramanik, N.; Kumar, S. High Electrochemical performance flexible solid-state supercapacitor based on co-doped reduced graphene oxide and silk fibroin composites. Energy 2017, 141, 1982-1988. [CrossRef]

42. Yun, Y.S.; Cho, S.Y.; Jin, H.J. Carbon aerogels based on regenerated silk proteins and graphene oxide for supercapacitors. Macromol. Res. 2014, 22, 509-514. [CrossRef] 
43. Ma, R.; Gordon, D.; Yushin, G.; Tsukruk, V.V. Robust and flexible micropatterned electrodes and micro-supercapacitors in graphene-silk biopapers. Adv. Mater. Interfaces 2018, 5. [CrossRef]

44. Ji, Y.; Li, Y.; Chen, G.; Xing, T. Fire-resistant and highly electrically conductive silk fabrics fabricated with reduced graphene oxide via dry-coating. Mater. Des. 2017, 133, 528-535. [CrossRef]

45. Sun, C.; Li, X.; Zhao, J.; Cai, Z.; Ge, F. A Freestanding polypyrrole hybrid electrode supported by conducting silk fabric coated with PEDOT:PSS and MWCNTs for high-performance supercapacitor. Electrochim. Acta 2019, 317, 42-51. [CrossRef]

46. Song, P.; Tao, J.; He, X.; Sun, Y.; Shen, X.; Zhai, L.; Yuan, A.; Zhang, D.; Ji, Z.; Li, B. Silk-inspired stretchable fiber-shaped supercapacitors with ultrahigh volumetric capacitance and energy density for wearable electronics. Chem. Eng. J. 2020, 386, 124024. [CrossRef]

47. Cao, J.; Wang, C. Highly conductive and flexible silk fabric via electrostatic self assemble between reduced graphene oxide and polyaniline. Org. Electron. 2018, 55, 26-34. [CrossRef]

48. Zhang, H.; Qiao, Y.; Lu, Z. Fully Printed ultraflexible supercapacitor supported by a single-textile substrate. ACS Appl. Mater. Interfaces 2016, 8, 32317-32323. [CrossRef]

49. Das, C.; Krishnamoorthy, K. Flexible microsupercapacitors using silk and cotton substrates. ACS Appl. Mater. Interfaces 2016, 8, 29504-29510. [CrossRef]

50. Tang, B.; Sun, L.; Kaur, J.; Yu, Y.; Wang, X. In-situ synthesis of gold nanoparticles for multifunctionalization of silk fabrics. Dyes Pigments 2014, 103, 183-190. [CrossRef]

51. Wang, P.; Zhang, G.; Li, M.Y.; Yin, Y.X.; Li, J.Y.; Li, G.; Wang, W.P.; Peng, W.; Cao, F.F.; Guo, Y.G. Porous carbon for high-energy density symmetrical supercapacitor and lithium-ion hybrid electrochemical capacitors. Chem. Eng. J. 2019, 375, 122020. [CrossRef]

52. Huang, W.; Zhang, A.; Liang, H.; Liu, R.; Cai, J.; Cui, L.; Liu, J. Novel fabrication of hollow and spinous NiCo 2 S 4 nanotubes templated by natural silk for all-solid-state asymmetric supercapacitors. J. Colloid Interface Sci. 2019, 549, 140-149. [CrossRef] [PubMed]

53. Liu, C.; Li, J.; Che, L.; Chen, S.; Wang, Z.; Zhou, X. Toward large-scale fabrication of triboelectric nanogenerator (TENG) with silk-fibroin patches film via spray-coating process. Nano Energy 2017, 41, 359-366. [CrossRef]

54. Sencadas, V.; Garvey, C.; Mudie, S.; Kirkensgaard, J.J.K.; Gouadec, G.; Hauser, S. Electroactive Properties of electrospun silk fibroin for energy harvesting applications. Nano Energy 2019, 66, 104106. [CrossRef]

55. Kim, K.N.; Chun, J.; Chae, S.A.; Ahn, C.W.; Kim, I.W.; Kim, S.W.; Wang, Z.L.; Baik, J.M. Silk fibroin-based biodegradable piezoelectric composite nanogenerators using lead-free ferroelectric nanoparticles. Nano Energy 2014, 14, 87-94. [CrossRef]

56. Lu, Z.; Zhang, H.; Mao, C.; Li, C.M. Silk fabric-based wearable thermoelectric generator for energy harvesting from the human body. Appl. Energy 2016, 164, 57-63. [CrossRef]

57. Zhang, X.S.; Guo, Y.B.; Wang, Y.; Zhang, H.; Brugger, J. A Transparent silk-fibroin-based triboelectric microgenerator for airflow energy harvesting. In Proceedings of the 2017 IEEE 12th International Conference on Nano/Micro Engineered and Molecular Systems, NEMS, Los Angeles, CA, USA, 9-12 April 2017; pp. $65-68$.

58. Tulachan, B.; Meena, S.K.; Rai, R.K.; Mallick, C.; Kusurkar, T.S.; Teotia, A.K.; Sethy, N.K.; Bhargava, K.; Bhattacharya, S.; Kumar, A.; et al. Electricity from the silk cocoon membrane. Sci. Rep. 2014, 4, 5434. [CrossRef] [PubMed]

59. Nambajjwe, C.; Musinguzi, W.B.; Rwahwire, S.; Kasedde, A.; Namuga, C.; Nibikora, I. Improving electricity from silk cocoons through feeding silkworms with silver nanoparticles. Mater. Today Proc. 2020, 28, 1221-1226. [CrossRef]

60. Mi, H.Y.; Li, H.; Jing, X.; He, P.; Feng, P.Y.; Tao, X.; Liu, Y.; Liu, C.; Shen, C. Silk and silk composite aerogel-based biocompatible triboelectric nanogenerators for efficient energy harvesting. Ind. Eng. Chem. Res. 2020, 59, 12399-12408. [CrossRef]

61. Gogurla, N.; Roy, B.; Park, J.Y.; Kim, S. Skin-contact actuated single-electrode protein triboelectric nanogenerator and strain sensor for biomechanical energy harvesting and motion sensing. Nano Energy 2019, 62, 674-681. [CrossRef]

62. Wen, D.L.; Liu, X.; Deng, H.T.; Sun, D.H.; Qian, H.Y.; Brugger, J.; Zhang, X.S. Printed silk-fibroin-based triboelectric nanogenerators for multi-functional wearable sensing. Nano Energy 2019, 66, 104123. [CrossRef]

63. Zhang, X.S.; Brugger, J.; Kim, B. A silk-fibroin-based transparent triboelectric generator suitable for autonomous sensor network. Nano Energy 2016, 20, 37-47. [CrossRef] 
64. Luo, Y.; Li, Y.; Feng, X.; Pei, Y.; Zhang, Z.; Wang, L.; Zhao, Y.; Lu, B.; Zhu, B. Triboelectric nanogenerators with porous and hierarchically structured silk fibroin films via water electrospray-etching technology. Nano Energy 2020, 75, 104974. [CrossRef]

65. Niu, Q.; Huang, L.; Lv, S.; Shao, H.; Fan, S.; Zhang, Y. Pulse-driven bio-triboelectric nanogenerator based on silk nanoribbons. Nano Energy 2020, 74, 104837. [CrossRef]

66. Kim, H.J.; Kim, J.H.; Jun, K.W.; Kim, J.H.; Seung, W.C.; Kwon, O.H.; Park, J.Y.; Kim, S.W.; Oh, I.K. Silk nanofiber-networked bio-triboelectric generator: Silk Bio-TEG. Adv. Energy Mater. 2016, 6. [CrossRef]

67. Ye, C.; Dong, S.; Ren, J.; Ling, S. Ultrastable and high-performance silk energy harvesting textiles. Nano-Micro Lett. 2020, 12. [CrossRef]

68. Wang, Y.; Yu, H.; Liu, H.; Fan, Y. Double coating of graphene oxide-polypyrrole on silk fibroin scaffolds for neural tissue engineering. J. Bioact. Compat. Polym. 2020, 35, 216-227. [CrossRef]

69. Jia, X.; Wang, C.; Zhao, C.; Ge, Y.; Wallace, G.G. Toward Biodegradable mg-air bioelectric batteries composed of silk fibroin-polypyrrole film. Adv. Funct. Mater. 2016, 26, 1454-1462. [CrossRef]

70. Majumder, S.; Dahiya, U.R.; Yadav, S.; Sharma, P.; Ghosh, D.; Rao, G.K.; Rawat, V.; Kumar, G.; Kumar, A.; Srivastava, C.M. Zinc oxide nanoparticles functionalized on hydrogel grafted silk fibroin fabrics as efficient composite dressing. Biomolecules 2020, 10, 710. [CrossRef]

71. Xin, W.; Zhang, Z.; Huang, X.; Hu, Y.; Zhou, T.; Zhu, C.; Kong, X.Y.; Jiang, L.; Wen, L. High-performance silk-based hybrid membranes employed for osmotic energy conversion. Nat. Commun. 2019, 10. [CrossRef]

72. Pereira, R.F.P.; Gonçalves, R.; Fernandes, M.; Costa, C.M.; Silva, M.M.; de Zea Bermudez, V.; Lanceros-Mendez, S. Bombyx Mori silkworm cocoon separators for lithium-ion batteries with superior safety and sustainability. Adv. Sustain. Syst. 2018, 2, 1800098. [CrossRef]

73. Fernandes, T.C.D.; Rodrigues, H.M.R.; Paz, F.A.A.; Sousa, J.F.M.; Valente, A.J.M.; Silva, M.M.; de Zea Bermudez, V.; Pereira, R.F.P. Highly conducting bombyx mori silk fibroin-based electrolytes incorporating glycerol, dimethyl sulfoxide and [Bmim]PF 6. J. Electrochem. Soc. 2020, 167, 070551. [CrossRef]

74. Pereira, R.F.P.; Brito-Pereira, R.; Gonçalves, R.; Silva, M.P.; Costa, C.M.; Silva, M.M.; De Zea Bermudez, V.; Lanceros-Méndez, S. Silk fibroin separators: A step toward lithium-ion batteries with enhanced sustainability. ACS Appl. Mater. Interfaces 2018, 10, 5385-5394. [CrossRef] [PubMed]

75. Reizabal, A.; Gonçalves, R.; Fidalgo-Marijuan, A.; Costa, C.M.; Pérez, L.; Vilas, J.L.; Lanceros-Mendez, S. Tailoring silk fibroin separator membranes pore size for improving performance of lithium ion batteries. J. Membr. Sci. 2020, 598, 117678. [CrossRef]

76. Jia, X.; Wang, C.; Ranganathan, V.; Napier, B.; Yu, C.; Chao, Y.; Forsyth, M.; Omenetto, F.G.; Macfarlane, D.R.; Wallace, G.G. A biodegradable thin-film magnesium primary battery using silk fibroin-ionic liquid polymer electrolyte. ACS Energy Lett. 2017, 2, 831-836. [CrossRef]

77. Lu, W.; Yu, P.; Jian, M.; Wang, H.; Wang, H.; Liang, X.; Zhang, Y. Molybdenum disulfide nanosheets aligned vertically on carbonized silk fabric as smart textile for wearable pressure-sensing and energy devices. ACS Appl. Mater. Interfaces 2020, 12, 11825-11832. [CrossRef] [PubMed]

78. Pan, P.; Hu, Y.; Wu, K.; Cheng, Z.; Shen, Z.; Jiang, L.; Mao, J.; Ni, C.; Ge, Y.; Wang, Z. Growth of $\mathrm{ZnCo}_{2} \mathrm{O}_{4}$ nanocubes on flexible biochar substrate derived from natural silk waste fabric for lithium-ion battery anode. J. Alloys Compd. 2020, 814, 152306. [CrossRef]

79. Wang, C.; Xie, N.H.; Zhang, Y.; Huang, Z.; Xia, K.; Wang, H.; Guo, S.; Xu, B.Q.; Zhang, Y. Silk-derived highly active oxygen electrocatalysts for flexible and rechargeable zn-air batteries. Chem. Mater. 2019, 31, 1023-1029. [CrossRef]

80. Xiang, M.; Wang, Y.; Wu, J.; Guo, Y.; Wu, H.; Zhang, Y.; Liu, H. Natural silk cocoon derived nitrogen-doped porous carbon nanosheets for high performance lithium-sulfur batteries. Electrochim. Acta 2017, 227, 7-16. [CrossRef]

81. De Oliveira, H.P.; Sydlik, S.A.; Swager, T.M. Supercapacitors from free-standing polypyrrole/graphene nanocomposites. J. Phys. Chem. 2013, 20, 10270-10276. [CrossRef]

(C) 2020 by the authors. Licensee MDPI, Basel, Switzerland. This article is an open access article distributed under the terms and conditions of the Creative Commons Attribution (CC BY) license (http://creativecommons.org/licenses/by/4.0/). 